\title{
PENGARUH CAMPURAN AIR LIMBAH (AIR SELOKAN) TERHADAP KUAT TEKAN BETON f'c 14.5 Mpa (K-175)
}

\author{
Rasiyo Hepiyanto ${ }^{1}$, Dwi Kartikasari ${ }^{2}$ \\ 1,2 Fakultas Teknik Universitas Islam Lamongan \\ email : rasiyoheppypsts@unisla.ac.id ; dwiksaripsts@unisla.ac.id
}

\begin{abstract}
In improving technological progress, the use of concrete as a building is very popular in Indonesia. Because it can utilize materials that are easily obtained such as crushed stone, gravel, sand, cement and water at a relatively cheap price. On a daily use basis often found in housing construction project workers who use waste water (Sewer Water) for concrete processing. This of course requires a closer inspection of the quality of the concrete produced. The data analysis method begins with the investigation of cement materials, coarse and fine aggregates. Mixing concrete using clean water (PDAM) as a reference and waste water (Sewer Water) from the Unisla flat building. From the analysis that has been done, it is obtained the results of the compressive strength test of concrete at the age of 7, 14 and 28 days by mixing clean water of $13.68 \mathrm{MPa}, 18.51 \mathrm{MPa}, 21.04 \mathrm{MPa}$, while the results of the concrete compressive strength test at ages 7, 14 and 28 days by mixing Wastewater (Sewer Water) at $9.99 \mathrm{MPa}, 13.35 \mathrm{MPa}$ and 15.36 $M P a$.
\end{abstract}

Keywords : Wastewater, Concrete, Compressive Strength

\begin{abstract}
Abstrak
Dalam meningkatkan kemajuan teknologi, pemakaian beton sebagai bangunan sangat popular di indonesia. Karena bisa memanfaatkan bahan yang mudah diperoleh seperti batu pecah, batu kerikil, pasir, semen dan air dengan harga yang relatif murah.Pada penggunaan sehari-hari sering dijumpai pada pekerja proyek pembangunan rumah tinggal yang menggunakan air limbah (Air Selokan) untuk pengerjaan pembetonan. Hal ini tentunya memerlukan pemeriksaan yang lebih teliti terhadap mutu beton yang dihasilkan. Metode analisa data dimulai dengan penyelidikan bahan semen, agregat kasar dan halus. Pencampuran beton menggunakan air bersih (PDAM) sebagai acuan dan air limbah (Air Selokan) dari gedung rusunawa Unisla. Dari analisa yang telah dilakukan didapat hasil pengujian kuat tekan beton pada umur 7, 14 dan 28 hari dengan pencampuran air bersih sebesar 13,68 Mpa, 18,51 Mpa, 21,04 Mpa, sedangkan hasil pengujian kuat tekan beton pada umur 7, 14 dan 28 hari dengan pencampuran Air Limbah (Air Selokan) sebesar 9,99 MPa, 13,35 MPa, dan 15,36 MPa.
\end{abstract}

Kata Kunci : Air Limbah, Beton, Kuat Tekan

\section{PENDAHULUAN}

Beton adalah suatu material yang terdiri dari campuran semen portland, air, agregat kasar (kerikil) dan agregat halus (pasir) serta bahan tambahan jika diperlukan. Campuran dari bahanbahan tersebut harus ditetapkan sedemikian rupa sehingga menghasilkan beton segar yang mudahdikerjakan. Beton merupakan salah satu bahan kontruksi yang seringkali diperlukan dalam struktur bangunan. Tingkat kebutuhan penggunaan beton dimasyarakan sebagai struktur bangunan sangat tinggi, Karena beton dinilai lebih praktis dan lebih ekonomis dibanding dengan material kontruksi yang lain, Dalam meningkatkan kemajuan teknologi, pemakaian beton 
sebagai bangunan sangat popular di indonesia. Dalam fenomena sekarang ini kebutuhan air yang memenuhi syarat dalam penggunaannya sudah mulai berkurang terutama pada kotakota besar atau pada negara-negara maju yang mana air bersih hanya diprioritaskan pada kebutuhan primer saja. Dunia teknik sipil terutama pada negara maju telah memikirkan tentang tantangan ke depan akan berkurangnya potensi air bersih (air tawar) yang dapat digunakan sebagai bahan campuran beton, terlebih pembangunan infrastruktur semakin meningkat seiring dengan penggunaan air bersih yang semakin banyak. Dari fenomena diatas, peneliti melihat potensi sumber Air Limbah (Air Selokan) yang begitu melimpah, maka ada pemikiran untuk menggunakan air limbah sebagai bahan pencampuran beton, yang terkhusus pada lokasi- lokasi bangunan yang kurangnya air bersih sebagai campuran beton. Pada penggunaan sehari- hari sering dijumpai pada pekerja proyek pembangunan rumah tinggal yang menggunakan Air Limbah (Air Selokan) untuk pengerjaan pembetonan. Hal ini tentunya memerlukan pemeriksaan yang lebih teliti terhadap metu beton yang dihasilkan. Oleh karena itu, penelitian ini cukup penting untuk dilakukan dengan satu harapan dapat mengetahui mutu beton dengan penggunaan Air Limbah (Air Selokan). Tujuan yang ingin dicapai dari penelitian ini adalah untuk mengetahui seberapa besar pengaruh campuran Air Limbah (Air Selokan) terhadap kuat tekan beton.

\section{METODE PENELITIAN}

Penelitian ini mengunakan metode eksperimen yaitu penelitian dengan percobaan langsung di Laboratorium Universitas Islam Lamongan (Unisla) yang bertujuan untuk menyelidiki hubungan sebab akibat anatara satu sama yang lain dan membandingkan hasilnya, beton yang diteliti merupakan beton dengan mengunakan campuran Air Limbah (Air Selokan) yaitu yang diambil dari Gedung Rusunawa (Unisla).

\subsection{Teknik Pengumpulan Data}

Pengumpulan data dilakukan untuk memperoleh informasi yang dibutuhkan dalam rangka mencapai tujuan penelitian. Data adalah sesuatu yang belum memiliki arti bagi penerimanya dan masih membutuhkan adanya suatu pengolahan. Data biasanya memiliki berbagai wujud, mulai dari gambar, suara, huruf, angka, bahasa, simbol, bahkan keadaan. Semua hal tersebut dapat disebut sebagai data asalkan dapat kita gunakan sebagai bahan untuk melihat lingkungan, obyek, kejadian, ataupun suatu konsep.

1. Data primer, yaitu data yang dikumpulkan dan diolah sendiri oleh peneliti langsung dari subjek atau objek penelitian.

2. Data sekunder, yaitu data yang didapatkan tidak secara langsung dari objek atau 
subjek penelitian.

\subsection{Analisa Data}

Penelitian ini dilakukan dengan menganalisa data dan bahan-bahan yang telah terkumpul, berikut adalah tahap analisa data yang nanti akan dilakukan dalam penelitian :

1. Alat Penelitian

- Molen (Concrete mixer)

- Cetakan silinder beton

- Alat pemadat

- Kerucut Abrams

- Ayakan

- Neraca atau Timbangan

- Mistar atau Meteran

- Gelas ukur

- Oven

- Mesin Uji Kuat Tekan (Hidrolis)

2. Bahan Penelitian

- Agregat Kasar

- Agregat Halus

- Semen

- Air limbah (Air Selokan)

3. Pelaksanaan penelitian

- Penyelidikan Bahan Semen

- Percobaan Konsistensi Normal Semen Portland

- Percobaan Waktu Mengikat dan Mengeras Semen

- Percobaan Menentukan Berat Jenis Semen

- Penyelidikan Bahan Pasir

- Percobaan Analisa Saringan Pasir

- Pengujian Kadar Air Agregat

- Percobaan Berat Jenis Pasir

- Percobaan Air Resapan Pasir

- Percobaan Bobot Isi dan Rongga Udara Dalam Pasir

- Penyelidikan Bahan Batu Pecah

- Percobaan Kelembapan Batu Pecah

- Percobaan Berat Jenis Batu Pecah 
- Percobaan Air Resapan Batu Pecah

- Percobaan Berat Volume Batu Pecah

- Percobaan Analisa Saringan Batu Pecah

- Pelaksanaan Campuran Beton

- Pembuatan Campuran Beton

- Slump Test

- Percobaan Mencetak Silinder Beton

- Proses Perawatan Beton

- Tes Kekuatan Tekan Hancur

\section{HASIL DAN PEMBAHASAN}

Pemeriksaan bahan penyusun beton yang dilakukan di Laboratortium Bahan Fakultas Teknik Universitas Islam Lamongan (Unisla), untuk bahan yang diperiksa adalah semen portland, agregat kasar dan agregat halus, Dari hasil pemeriksaan bahan penyusun beton didapat hasil sebagai berikut:

\subsection{Hasil Kuat Tekan Beton}

Pengujian ini dilakukan saat umur beton silinder mencapai umur 7 dan dikorelasi ke umur 14, 28 hari, Pengujian dilakukan dengan bantuan mesin kuat tekan beton (Hidrolis), data hasil penujian kuat tekan beton ditunjukkan pada tabel 1, 2 dan 3 serta grafik pada gambar 1, didapat nilai kuat tekan beton, sebagai berikut:

Tabel 1: Hasil Kuat Tekan Umur 7 Hari

\begin{tabular}{|c|c|c|c|c|c|c|c|c|c|c|}
\hline $\begin{array}{l}\text { Kode } \\
\text { Beton }\end{array}$ & $\begin{array}{l}\text { Uluran } \\
\text { (cm) }\end{array}$ & $\begin{array}{l}\text { Lusa } \\
\text { Pensmpang } \\
\text { (cm) }\end{array}$ & $\begin{array}{l}\text { Umur } \\
\text { (hari) }\end{array}$ & $\begin{array}{l}\text { Berat } \\
(\mathrm{kg})\end{array}$ & $\begin{array}{l}\text { Volume } \\
\text { Cilinder } \\
\text { Beton } \\
\left(m^{2}\right)\end{array}$ & $\begin{array}{l}\text { BJ } \\
\text { Beton } \\
\left(\mathrm{kg} / \mathrm{m}^{2}\right)\end{array}$ & $\begin{array}{l}\text { Telianan } \\
\text { Hancur } \\
(\mathrm{kg})\end{array}$ & $\begin{array}{l}\text { Hasil Uji } \\
\text { Telsan } \\
3 \mathrm{~b} / \mathrm{I} \\
(\mathrm{kg} / \mathrm{cm} 2)\end{array}$ & $\begin{array}{l}\text { Teg. } \\
\text { Hancur } \\
7 \text { hari } \\
\text { (Mps) }\end{array}$ & $\begin{array}{l}\text { Rata- } \\
\text { rata } \\
\text { Kuat } \\
\text { telian } \\
\text { twyes }\end{array}$ \\
\hline $\begin{array}{l}\text { Air } \\
\text { Bersih }\end{array}$ & F $15-30$ & 176.625 & 7 & 12.255 & 0.5300 & 23.12 & 29000 & 164.19 & 13.369 & \\
\hline $\begin{array}{l}\text { Air } \\
\text { Bersih }\end{array}$ & F $15-30$ & 176.625 & 7 & 12.551 & 0.5300 & 23.68 & 30000 & 169.85 & 13.830 & 13.68 \\
\hline $\begin{array}{l}\text { Air } \\
\text { Bersih }\end{array}$ & F $15-30$ & 176.625 & 7 & 12.587 & 0.5300 & 23.75 & 30000 & 169.85 & 13.830 & \\
\hline $\begin{array}{l}\text { Air } \\
\text { Limbah }\end{array}$ & F $15-30$ & 176.625 & 7 & 12.286 & 0.5300 & 23.18 & 21000 & 118.90 & 9.681 & \\
\hline $\begin{array}{l}\text { Air } \\
\text { Limbah }\end{array}$ & F $15-30$ & 176.625 & 7 & 12.311 & 0.5300 & 23.23 & 24000 & 135.88 & 11.064 & 9.99 \\
\hline $\begin{array}{l}\text { Air } \\
\text { Limbah } \\
\text { Sumber }\end{array}$ & F $15-30$ & 176.625 & 7 & 12.156 & 0.5300 & 22.94 & 20000 & 113.23 & 9.220 & \\
\hline
\end{tabular}


Tabel 2: Hasil Kuat Tekan Umur 14 Hari (Dikorelasi)

\begin{tabular}{|c|c|c|c|c|c|c|}
\hline Kode & Umur & $\begin{array}{c}\text { nilai } \\
\text { sorelast }\end{array}$ & $\begin{array}{c}\text { Tegangan Hacut } \\
\qquad\left(\mathrm{A} g \mathrm{Bn}^{2}\right)\end{array}$ & $\begin{array}{c}\text { Teg. } 14 \mathrm{bz} \\
(\mathrm{kg}, \mathrm{c}=2)\end{array}$ & $\begin{array}{c}\text { Teg. Hancur } 14 \\
\text { hari (Mpa) }\end{array}$ & $\begin{array}{c}\text { Ras.rata } \\
\text { kust was } \\
\text { (Noa) }\end{array}$ \\
\hline Air Bersih & 7 hari & 0.88 & 164.19 & 186.579 & 15.192 & \multirow{3}{*}{18.51} \\
\hline Air Bersih & 7 hari & 0.88 & 169.85 & 193.013 & 15.716 & \\
\hline Air Bersih & 7 hari & 0.88 & 169.85 & 193.013 & 15.716 & \\
\hline Air limbsh & 7 hari & 0.88 & 118.90 & 135.109 & 11.001 & \multirow{3}{*}{13.52} \\
\hline Air limbah & 7 hari & 0.88 & 135.88 & 154.410 & 12.573 & \\
\hline Air limbah & 7 hari & 0.88 & 113.23 & 128.675 & 10.477 & \\
\hline
\end{tabular}

Sumber : Hasil Penelitian 2017

Tabel 9 Hasil Kuat Tekan Umur 28 Hari (Dikorelasi)

\begin{tabular}{|c|c|c|c|c|c|c|}
\hline Kode & Umur & $\begin{array}{l}\text { Nilai } \\
\text { Kotelasi }\end{array}$ & $\begin{array}{c}\text { Tegangas } \\
\text { Hascu: } \\
\left(\mathrm{X}_{2} / \mathrm{Cm}^{2}\right)\end{array}$ & $\begin{array}{c}\text { Teg. } 28 \\
\text { Ban } \\
(\mathrm{Kg} / \mathrm{C}=2)\end{array}$ & $\begin{array}{c}\text { Teg. Hancur } 28 \\
\left.\text { Hari } p_{(y)}\right)\end{array}$ & $\begin{array}{c}\text { Rasa-rata } \\
\text { kust } \\
\text { toxas } \\
\text { (Nos) }\end{array}$ \\
\hline Air Bersih & $\begin{array}{c}7 \\
\text { Hari }\end{array}$ & 0.65 & 164.19 & 252.599 & 20.567 & \multirow{3}{*}{21.04} \\
\hline Ait Bersih & 7 & 0.65 & 169.85 & 261.310 & 21.277 & \\
\hline Air Bersih & $\begin{array}{r}\text { Ban } \\
7 \\
\text { Bari }\end{array}$ & 0.65 & 169.85 & 261.310 & 21.277 & \\
\hline Air limbah & $\begin{array}{r}7 \\
\text { Hari }\end{array}$ & 0.65 & 118.90 & 182.917 & 14.894 & \multirow{3}{*}{15.36} \\
\hline Az lambah & $\begin{array}{c}7 \\
\text { Han }\end{array}$ & 0.65 & 135.88 & 209.048 & 17021 & \\
\hline Air limbah & $\begin{array}{r}7 \\
\text { Hari } \\
\end{array}$ & 0.65 & 113.23 & 174.207 & 14.184 & \\
\hline
\end{tabular}

Sumber : Hasil Penelitian. 2017 


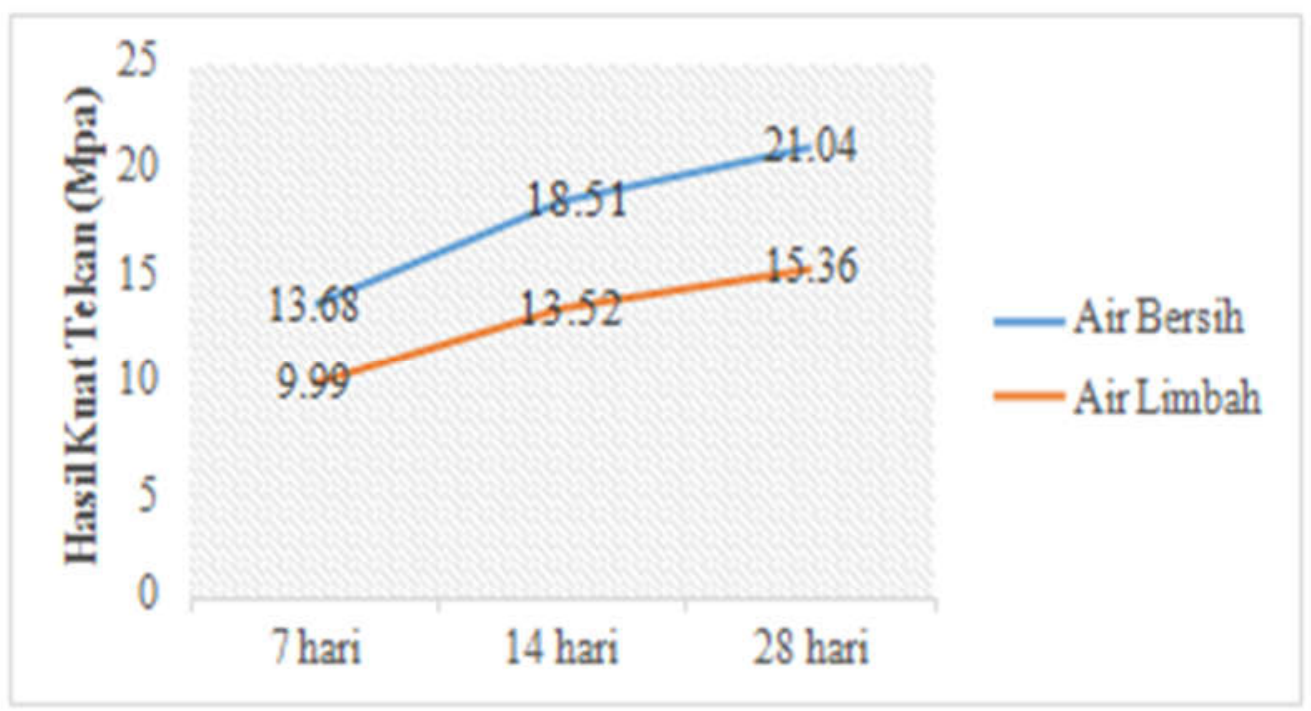

Gambar 1: Grafik Kuat Tekan

Berdasarkan hasil pengujian kuat tekan menurut Gambar 3 dapat diketahui bahwa nilai kuat tekan beton dari masing-masing campuran beton terhadap jenis air yang berbeda mengalami peningkatan nilai kuat tekan rata-rata yang terjadi pada umur 7, 14 dan 28 hari dengan campuran Air Bersih sebesar 13,68, 18,51, 21,04 Mpa, Sedangkan nilai kuat tekan rata-rata yang menggunakan Air Limbah (Air Selokan) sebesar 9,99 MPa, 13,52 MPa, dan 15,36 MPa.

\section{KESIMPULAN}

\subsection{Kesimpulan}

Setelah dilakukan pengujian material, pembuatan benda uji, pengujian kuat tekan, dan perhitungan, maka dari penelitian ini dapat diambil beberapa kesimpulan sebagai berikut :

Hasil pengujian kuat tekan beton pada umur 7, 14 dan 28 hari dengan pencampuran Air Bersih sebesar 13,68 Mpa, 18,51 Mpa, 21,04 Mpa, sedangkan hasil pengujian kuat tekan beton pada umur 7, 14 dan 28 hari dengan pencampuran Air Limbah (Air Selokan) sebesar 9,99 $\mathrm{MPa}, 13,52 \mathrm{MPa}$, dan 15,36 MPa.

\subsection{Saran}

Untuk penyempurnaan hasil serta mengembangkan penelitian yang lebih lanjut, penulis menyarankan hal-hal sebagai berikut :

1. Perlu dilakukan penelitian lebih lanjut mengenai penggunaan Air Limbah (Air Selokan) dari beberapa sumber berbeda dalam campuran beton, dengan umur pengujian kuat tekan beton yang berbeda.

2. Melakukan penelitian lebih lanjut mengenai uji kimia pada Air Limbah (Air Selokan) 
terhadap kuat tekan beton.

Penggunaan Air Limbah (Air Selokan) Gedung Rusunawa Unisla hanya boleh digunakan apabila dalam kondisi betul-betul tidak ada air lain, maksimal penggunaan hanya diperbolehkan untuk rumah sederhana 1 lantai, hal ini dikarenakan dari hasil penelitian pemakaian Air Limbah (Air Selokan) tidak memenuhi mutu rencana kuat tekan secara signifikan dibanding Air PDAM.

\section{DAFTAR PUSTAKA}

[1] Ardiyansyah, Aditya, 2014, Pengaruh Penggunaan Air Rawa, Air Pdam Dan Air Laboratorium Disaring Terhadap Umur Dan Kuat Tekan Beton. Fakultas Teknik Universitas Bengkulu, Bengkulu.

[2] Cahyadi, Wahyu Dwi, 2012, Judul Studi Kuat Tekan Beton Normal Mutu Rendah Yang Mengandung Abu Sekam Padi (Rha) Dan Limbah Adukan Beton (Csw),Fakultas Teknik Sipil Universitas Indonesia, Jakarta.

[3] Chandra, Johanes, 2008, Pengaruh Pemakaian Cacahan Limbah Gelas Plastik Polypropylene (Pp) Pada Kuat Tarik Dan Kuat Lentur Material Beton, Fakultas Teknik Universitas Indonesia, Jakarta.

[4] Hendriyani, Irna dkk, 2016 Pengaruh Jenis Air Pada Perawatan Beton Terhadap Kuat Tekan Beton Pdf, Program Studi Teknik Sipil Universitas Balikpapan. Balikpapan

[5] Meliani, Leni Puspa, 2013, Studi Perbandingan Sifat Mekanis Beton Dengan Dan Tanpa Perkuatan Gfrp Dan Tyfo Sw Epoxy (Underwater). Fakultas Teknik Universitas Lampung. Lampung.

[6] Widiyanto, Acep, dkk 2016, Pengaruh Agregat Kasar Terhadap Kuat Tekan Beton Dengan Agregat Kasar Pecahan Bata Ringan (Variasi Agregat Kasar Lolos Saringan $16 \mathrm{Mm}, 22,4 \mathrm{Mm}$ Dan 25Mm) Pdf, Universitas Muhamadiyah Yogyakarta, Yogyakata.

[7] SK SNI - 04 - 1991. Persyaratan Pemakaian Air untuk Campuran Beton.

[8] SNI 15-2049-2004 Standart Nasional Indonesia Semen Portland.

[9] Aditya, C. (2010). Pengaruh penggunaan limbah pasir onyx sebagai bahan pengganti pasir pada Kuat lentur, rembesan dan penyerapan air genteng beton. Widya Teknika, 18(2).

[10] Rajagukguk, A. (2015). Pengaruh Penambahan Limbah Debu Pengolahan Baja (Dry Dust Collector) dan Penambahan Serat Polypropylene Terhadap Sifat 
Mekanis Beton. Jurnal Teknik Sipil USU, 5(1).

[11] Dewi, N. R., Dermawan, D., \& Ashari, M. L. (2016). Studi Pemanfaatan Limbah B3 Karbit Dan Fly Ash Sebagai Bahan Campuran Beton Siap Pakai (BSP)(Studi Kasus: PT. Varia Usaha Beton). Jurnal Presipitasi, 13(1), 34-43.

[12] Candra, A. I. (2017). ANALISIS DAYA DUKUNG PONDASI STROUS PILE PADA PEMBANGUNAN GEDUNG MINI HOSPITAL UNIVERSITAS KADIRI. Ukarst, 1(1), 63-70.

[13] Ervianto WI, 2002, Teori Aplikasi Manajemen Proyek Konstruksi, Andi, Yogyakarta. Yogyakarta.

[14] L.Wahyudi, Syahril A.R, 1999, Struktur Beton Bertulang (SNI T-15-1991-03), Gramedia, Jakarta.

[15] Paul Nugraha, 2007, Teknologi Beton Dari Material, Pembuatan, Ke Beton Kinerja Tinggi, LPPM Univ. Kristen Petra, Surabaya.

[16] Pujo Aji, Rachmat Purwono, 2010, Pengendalian Mutu Beton, ITS Press, Surabaya.

[17] Suharto Iman, 1999, Manajemen Proyek Dari Konseptual Sampai Operasional Jilid I, II, Erlangga, Jakarta. 